Vol. 38(1), pp. 47-59, June 2019

ISSN 1821-536X (print)

ISSN 2619-8789 (electronic)
Tanzania Journal of Engineering and Technology

Copyright (C) 2019 College of Engineering and

Technology, University of Dar es Salaam

Full Length Research Paper

\title{
Experimental Study on the Effect of Moisture on Bolt Embedment and Connection Loaded Parallel to Grain for Timber Structures
}

\author{
Henry M. Kiwelu \\ Department of Structural and Construction Engineering, College of Engineering and Technology, \\ University of Dar es Salaam, P.O. Box 35131, Dar es Salaam, Tanzania. \\ E-mail: hekimaus2005@gmail.com
}

\begin{abstract}
Connections are critical parts of timber structures, transmitting static and dynamic forces between structural elements. The ultimate behaviour of a building depends strongly on the structural configuration and the capacity of its connections. The complete collapse of a building or other less extensive accidents that may occur usually start as a local failure inside or in the vicinity of a joint. The main aim of this study has been to investigate if the short-term capacity of steel-wood dowel joints loaded parallel to the grain is affected by variations in moisture content associated with post fabrication drying or wetting of the timber. Extensive experiments were conducted. The experimental results showed that the stiffness and load-bearing capacity of the joints is reduced by post-fabrication wetting and is increased by post-fabrication drying. It was clear from those test results that changes in mechanical properties were greater than could be explained by effects moisture content changes have on material properties, implying that simple adjustments of properties in that way for purposes of structural design are unreliable Currently in the design of timber connection in code of practise is the effect of variation of moisture is not considered. The results revealed that there is a great effect on timber performance which is due to an increase of moisture content.
\end{abstract}

Keywords: Beam, creep, wood, heat transfer, hydrothermal strain, moisture strain.

\section{INTRODUCTION}

The mechanical performances of timber connections are particularly important for timber engineers involved in the design of the wood structures. In the existing codes of practise there is no consideration of the effect of moisture change of timber in service. In general, joints are often one of the weakest links in timber structures. The mechanism of connection must be well understood in order to design a safe connection and avoid catastrophic failure. Often connections are made weak fuse elements by deliberate intent to ensure that if structural systems fail it will be by controllable ductile deformation of connections in load paths, instead of brittle timber element failures. This is an important difference compared, for example, to structural steel or reinforced concrete structures where connections are typically designed to be strong elements in load paths. Timber connections are complex to model due to the fact that they are affected by several factors such as geometry, type of fasteners, and moisture content of timber elements, loading duration, and density of wood. The effect of the factors above, and others, should all be considered in the design of timber connections. 
European yield models EYMs developed by Johansen (1949) are the most widely accepted means for making strength predictions for wood connections with laterally loaded dowel fasteners (Smith et al., 2006). These mathematical models, of which many variations have been developed by various people, predict the capacity per fastener based on the assumption that plastic deformations govern when failure occurs. EYM set up a series of alternative failure mechanisms involving fully plastic yielding in either the fastener or the wood "foundation" beneath, or yielding in both fastener and foundation (Whale, 1988).

Timber/wood is a colloidal, porous, nonhomogeneous and anisotropic material that can be challenging to process and utilize due to numerous interactions that influence dimensions during and after processing (Asiz and Smith, 2009). Processes that control dimensional changes are thermomechanosportive and time dependant (Miriano et al., 2008). However, other construction materials, most importantly metals like steel are relatively dimensionally stable unless heated excessively, which does not occur during normal use of buildings (Rammer, 2001). In hybrid structures various materials must work together mechanically when interconnected to create composite components or building substructures (Ranta-Manus, 2003). The ability of joined materials to effectively work together depends on their capability to remain intact and/or interconnected under separate or combined influences of external mechanical, hygro- thermal and chemical reaction process loads that occur and vary throughout the lifetimes of buildings (commencing with their construction and ending with their demolition) (Asiz and Smith, 2009).

Timber/wood materials normally undergo shrinkage when installed in buildings as bound water escapes from the amorphous areas of cellulose chains allowing them to move closer because the surrounding air tends to be unsaturated (Eriksson, 2005). Although shrinkage that occurs after timber and woodbased products are installed is not a stress-free process, the drying stresses caused then can be minimized by using pieces having moisture content close to what they will achieve in service (Jönsson, 2004). Timber may shrink or expand while in service after initial drying because of the moisture difference between the environment and wood members (Dinwoodie, 2000).

The bolted wood connection appears to a casual observer to have fairly simple behaviour, but the connection mechanics is extremely complex (Smith et al, 2006). The design of bolted wood connections is based on the European yield model which was developed by Johansen (1949) and is known as EYM-1949. This model incorporates the effect of wood embedment strength and bolt yielding to predict the capacity of single bolt connections. For joints with relatively large member thickness to bolt diameter ratio, a considerable amount of ductility is observed prior to failure and hence this proves the applicability of EYM theory in these types of connections. The EYM theory applies to slender bolts and other metallic dowel fasteners like timber rivets drift pins, nails, screws etc. In case of small member thickness to bolt ratio and when the load is applied parallel to grain the failures have been noticed to be of brittle mode with no or very minor ductility before it reaches failure (Smith et al., 2002). In such cases the EYM is not able to predict the exact failure load and hence not reliable for such design. In a study that was done by Quenneville and Mohammed (2000; 2001) it was shown that the load is not uniformly distributed in a row of thicker bolts. The global failure for such connections is basically brittle although some individual bolts may experience minor ductility.

In its revision of CSA (1994; 2009), CSA has provided a new modification factor which accounts for premature brittle failure (resistance factor for brittle failure) with suboptimum loaded end distance and bolt 
group action in failure associated with suboptimum load end distance and bolt group action in connection. However, the basis of this modification factor is empirical due to high number of parameters that influence the performance of timber joints. These parameters include the variability of wood species, moisture content of the wood, thickness of wood, diameter of bolt used, edge distance, spacing of the bolts, etc. Recent publications have shown the need of moving from design based on empirical finding and experience to more fundamental understanding of material behaviour and mechanical principles (Kharouf et al., 2005).

Dowel bearing strength is a material property, determined experimentally, that describes a limit-state stress in the wood around a pin loaded hole in compression. The dowel bearing strength is the important information which is used in EYM to estimate the failure loads by using the lower values from the equations provided in CSA (2009). Embedment strength is considerably influenced by loading direction (parallel or perpendicular to grain) not only because of a different modulus of elasticity of wood when compressed parallel or perpendicular to grain, but also on account of a different failure mode (Quenneville et al., 2000). The embedment strength has also been pointed to be affected by among other factors such as density and bolt diameter as well as moisture content (Rammer and Winistorfer, 2001). The main aim of this study was to investigate if the short-term capacity of steel wood dowel joints loaded parallel to the grain is affected by variations in moisture content associated with post fabrication drying or wetting of the timber.

\section{METHODS AND MATERIALS}

\section{Bolt Load Transfer Mechanism to Wood}

The primary load transfer mechanism in bolted wood connections is bearing of the bolt on the hole in the connected members. Force is transferred through contact surface of bolt and wood point $\mathbf{O}$ (Figure 1). Wood connections (wood -steel-wood) with larger aspect ratios ( $\mathrm{L} / \mathrm{d}$ greater than 2) will have no uniform bearing stresses through the member thickness due to significant bending of the bolt. Steel connections usually have a small aspect ratio $(\mathrm{L} / \mathrm{d}$ less than 1$)$. Friction between connecting members is not a reliable load transfer mechanism in bolted wood connections because member shrinkage can cause gaps to form.

In laboratory experiments it is necessary to drill the hole slightly larger than the diameter of the bolt to ease installation and allow for small misalignment of members. Therefore common practice in bolted wood connections is to manufacture the holes $1.5 \mathrm{~mm}$ larger than the bolt. The effect of bolt/hole clearance and changing contact area for bolted connections in anisotropic materials (including wood) has been studied by Smith et al. (2002).

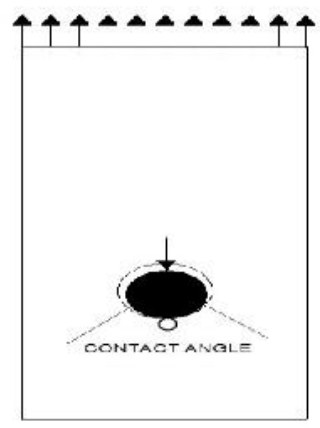

\section{Figure 1: Wood bolt load transfer} mechanism

The behaviour of joints in wood structures, like other mechanical properties of wood is affected by moisture content $(u)$ which affects the strengths, stiffness and failure mechanism of connections. The serviceability and the safety of timber structures can be significantly affected by the combination of humidity history and mechanical loading (Jönsson, 2004; Sjodin, 2007). Ranta-Maunus (2003) explained the mechanical consequences of the moisture content in wood caused by a naturally varying climate. In function of the location of a building, the kind of building and its use, wood is not exposed to the same relative humidity. In the last decade, several 
computational methods have been introduced for the evaluation of moisture induced stresses in wood (Ormarsson, 1999). In the presence of moisture content changes, the shrinkage can cause relatively high deformations of the wood elements, but the stiffness of the steel components makes the connections rigid and may produce high values of the stresses, particularly in the cross-grain direction (Miriano et al., 2008).

\section{Bolted Wood Connection Test}

The purpose of the bolted connection tests was to characterise the influence of moisture content of glulam members on connection specimen's representative of methods used in elsewhere to join elements in glulam superstructures frameworks. Tests were therefore devised to elucidate effects of variations in initial average moisture contents and changes in average moisture movements due to drying in situations where bolts either do or do not constrain deformation of glulam. The deformation constraints occur in multiple bolt connections and result from combined effects of differential stiffness characteristics of glulam and steel plates, bolt stiffness in bending, glulam thickness, number of bolts employed and the arrangement of them, and initial average moisture content of the glulam and subsequent variations in it. Design of the experiments was to account for all the complex influences involved. The tests were conducted using specimens of types shown in Figure 2 and 3. The reason for testing arrangements with bolts placed side by side in the perpendicular to grain direction is that it is the situation most prone to creation of stresses perpendicular to grain that can cause drying cracks. Single bolt connections were tested because that is the reference case on which design practices are based. Edge, end and spacing distances employed were based on requirements of the timber design code (Euro code 5). The steel plates were always $6.0 \mathrm{~mm}$ thick. The complete schedule of connection tests is given in Table 1 .
Provided that steel plates have adequate thickness, which is nearly always the case, bolted plate connections fail by crushing glulam directly under the bolt(s), opening or forward-shear fracturing of glulam, bending yield failure of bots, or some combination of the various associated mechanisms. Figure 4(a) to (d) show possible modes of failure for a single fastener joint loaded in tension parallel to grain.

\section{Specimen Preparation and Moisture Conditioning}

Specimens were prepared by cutting the square ended slots at the centre plane of glulam member specimens in order to accommodate steel plates using a wood miser sawing machine with a $2 \mathrm{~mm}$ thick blade. Holes for bolts were pre-drilled to be oversized by $1 / 16$ inch $(1.6 \mathrm{~mm})$, which matched the method of drilling for embedment specimens in all respects. Bolt holes in steel plates were drilled to diameters of $14.3 \mathrm{~mm}$ and $20.7 \mathrm{~mm}$ for $1 / 2$ inch and $3 / 4$ inch bolts. After assembly of connections specimens' groups of them were placed in conditioning chamber set to attain target equilibrium moisture contents of 8,12 or $17 \%$.

Material for glulam members was carefully chosen to avoid inclusion of knots in the connection zone as per the requirements of the European timber design code (EC-05), and had lengths of $600 \mathrm{~mm}$ for tension specimens with $1 / 2$ inch bolts and $1000 \mathrm{~mm}$ for compression specimens with $3 / 4$ inch bolts. All the glulam pieces were initially stored in a climate of $20^{\circ} \mathrm{C}$ and $65 \%$ relative humidity until they reached an equilibrium moisture content of about $12 \%$. Glulam pieces were then randomly assigned to sets for conditioning to moisture contents of 8,12 or $17 \%$, as was done for embedment tests. Specimens conditioned to a target $u$ of $12 \%$ took four weeks to attain equilibrium moisture content, and specimens dried to a target $u$ of $8 \%$ took ten weeks to attain equilibrium moisture content. Tension test specimens were fabricated with a connection at each 
end, i.e. a steel plate and a bolt(s) at each end (Figure 6A). Specimens for compression tests had a connection at one end only, which was the top end when those specimens were loaded (Figure 6B). Bolts were inserted with circular steel washers of thickness $2.5 \mathrm{~mm}$
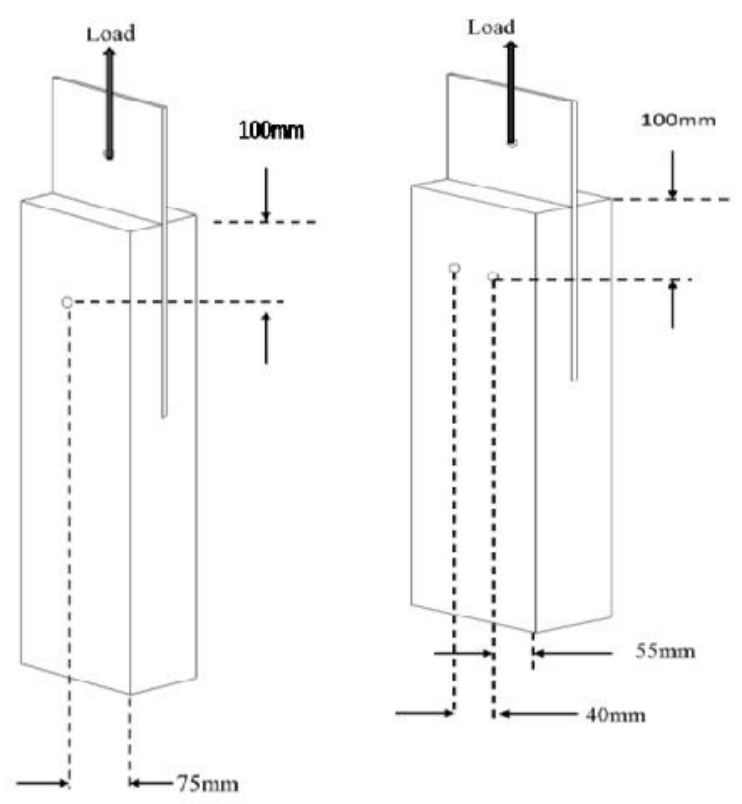

(a) one $12.7 \mathrm{~mm}$ bolt, $t=90 \mathrm{~mm}$, (b) two side by side 12.7 $\mathrm{mm}$ bolts, $t=90 \mathrm{~mm}$

Test moisture contents $8 \%, 12 \%$ and $17 \%$ and $24 \mathrm{~mm}$ outside diameter placed beneath their heads and nuts, with nuts made finger tight. Table 1 shows the schedule of connection tests done in the laboratory.
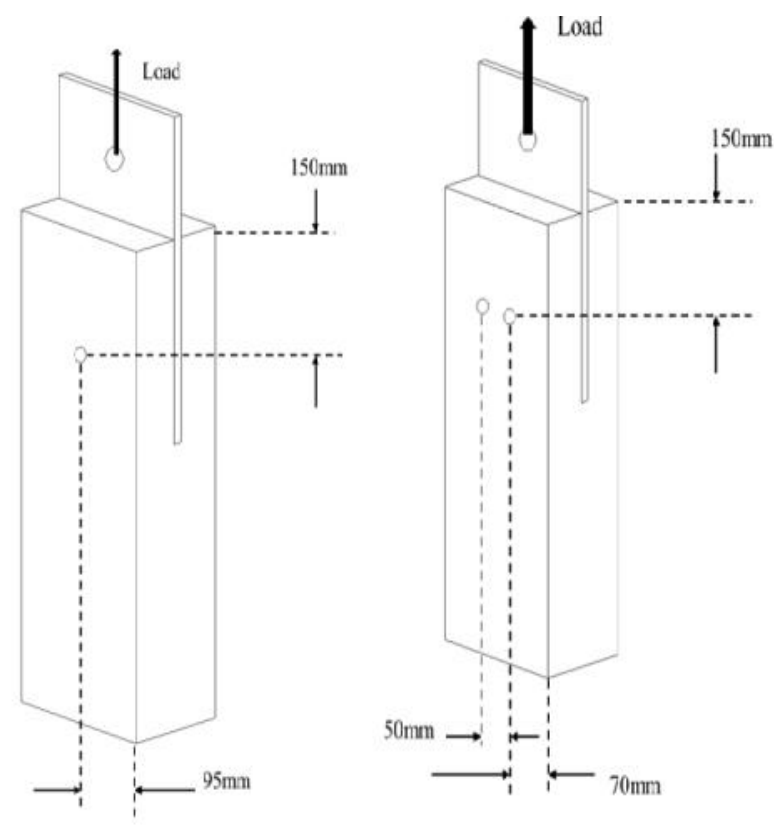

(c) one $19.1 \mathrm{~mm}$ bolt, $t=130 \mathrm{~mm}$, (d) two side by side $19.1 \mathrm{~mm}$ bolts, $t=130 \mathrm{~mm}$ Test moisture contents $8 \%, 12 \%$ and $17 \%$

Figure 2: Specimen loaded parallel to grain

\section{Table 1: Schedule of connection tests}

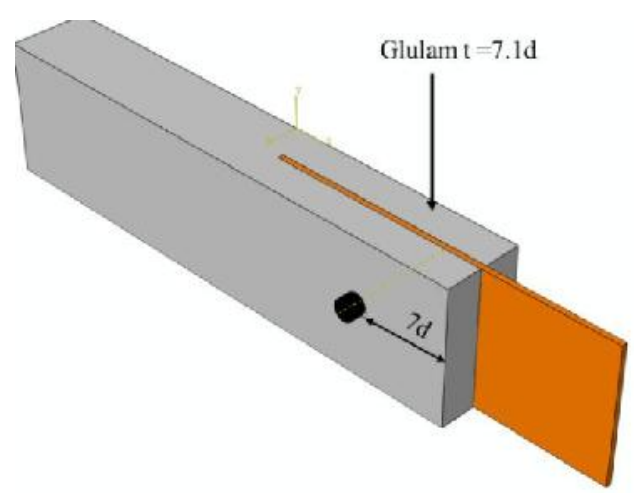

a) Single bolt connection

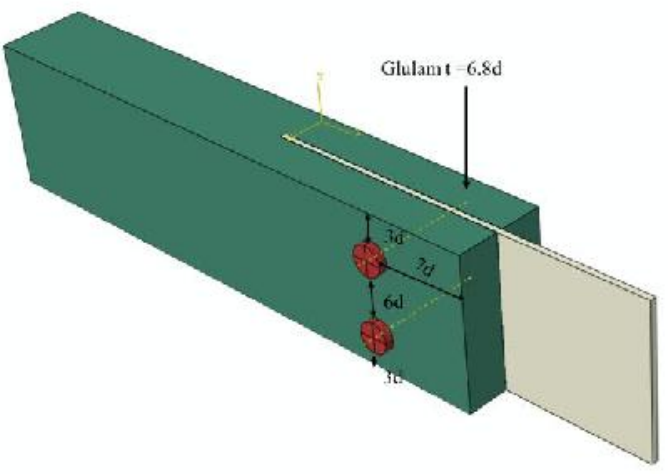

b) Double bolt connection

Figure 3: Spacing, end and edge distances employed $(\mathrm{d}=$ bolt diameter) 
Experimental Study on the Effect of Moisture on Bolt Embedment and Connection Loaded Parallel to Grain for Timber Structures

\begin{tabular}{|c|c|c|c|c|c|c|}
\hline \multirow{2}{*}{$\begin{array}{l}\text { Specimen } \\
\text { type }\end{array}$} & \multicolumn{2}{|l|}{ Bolts } & \multicolumn{2}{|l|}{ Glulam } & \multirow{2}{*}{$\begin{array}{l}\text { Moisture } \\
\text { content at } \\
\text { test, } u(\%)\end{array}$} & \multirow{2}{*}{$\begin{array}{l}\text { Number of } \\
\text { replicates }\end{array}$} \\
\hline & $d(\mathrm{~mm})$ & number & $\begin{array}{l}\text { thickness, } \\
t(\mathrm{~mm})\end{array}$ & $\begin{array}{l}\text { width, } \\
\text { w (mm) }\end{array}$ & & \\
\hline B12-S-8 & 12.7 & 1 & 90 & 150 & 8 & 8 \\
\hline B12-S-12 & 12.7 & 1 & 90 & 150 & 12 & 8 \\
\hline B12-S-17 & 12.7 & 1 & 90 & 150 & 17 & 8 \\
\hline B19-S-8 & 19.1 & 1 & 130 & 190 & 8 & 8 \\
\hline B19-S-12 & 19.1 & 1 & 130 & 190 & 12 & 8 \\
\hline B19-S-17 & 19.1 & 1 & 130 & 190 & 17 & 8 \\
\hline B12-D-8 & 12.7 & 2 & 90 & 150 & 8 & 8 \\
\hline B12-D-12 & 12.7 & 2 & 90 & 150 & 12 & 8 \\
\hline B12-D-17 & 12.7 & 2 & 90 & 150 & 17 & 8 \\
\hline B19-D-8 & 19.1 & 2 & 130 & 190 & 8 & 8 \\
\hline B19-D-12 & 19.1 & 2 & 130 & 190 & 12 & 8 \\
\hline B19-D-17 & 19.1 & 2 & 130 & 190 & 17 & 8 \\
\hline
\end{tabular}

Loading Direction

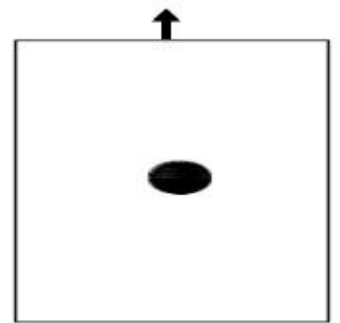

(a)

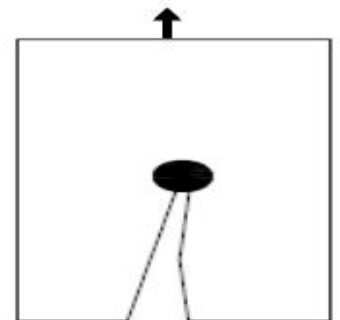

(b)

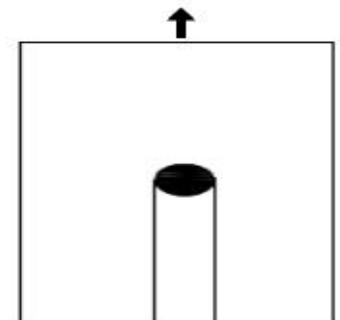

(c)

(a) Bearing failure

(b) Open mode fracture

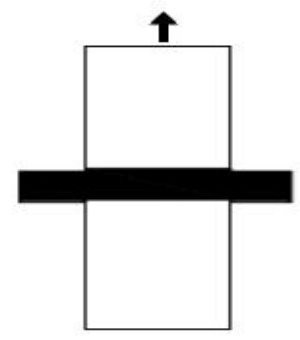

(d)

(d) Bolt failure

Figure 4: Possible failure mechanisms for a single bolt connection

Making nuts finger tight allowed specimens to self-align when subsequently load was applied by a Material Testing Machine (MTS) hydraulic loading machine. After fabrication specimens were placed into conditioning chambers set to achieve the target moisture contents. Figure 5 shows specimens conditioned to a target $u$ of $17 \%$ in a climate of $90 \%$ relative humidity and $67^{\circ} \mathrm{C}$, which took more than 10 weeks before specimen weights were constant (i.e. equilibrium moisture contents were reached).

The moisture conditioning regimes were intended to simulate glulam arriving at a construction sites (at $u$ of about 12\%) and then being installed in service climates that dried, kept moisture stable or wetted the glulam. This reflects that shrinkage and swelling is the most likely reason for damage to connections in superstructures that have never been loaded beyond application of forces associated with normal use of buildings and normal external loads like wind or snow pressures (Smith et al., 2002).

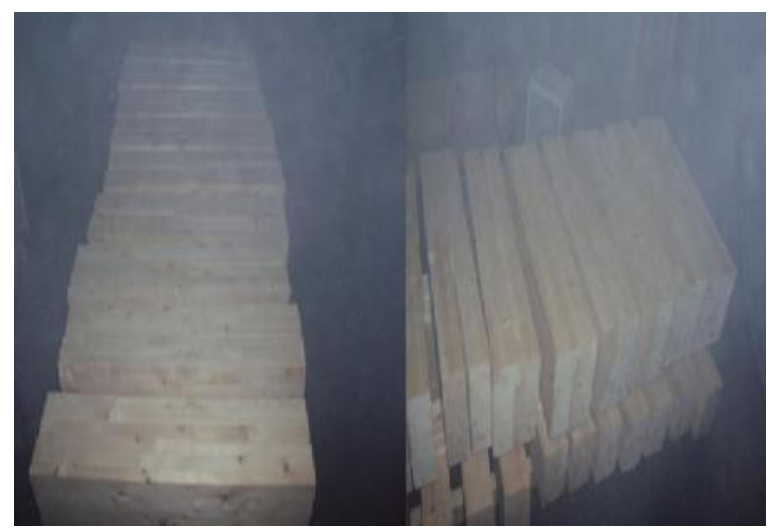

Figure 5: Specimens in conditioning to target moisture content of $17 \%$ 
Connection specimens were tested at a displacement-control rate of $1 \mathrm{~mm} / \mathrm{min}$ until failure, with failure being defined as having occurred following an unrecoverable drop in load carrying capability. Load was measured using a $250 \mathrm{kN}$ load cell and displacement slip was measured using two Linear Variable Displacement Transducers (LVDTs) with 140 $\mathrm{mm}$ displacement ranges. The LVDTs were mounted on opposite faces of the glulam members and recorded displacement of steel plates relative to glulam member. Thus, measured displacements were slip in connections rather than extensions of specimens. During post processing of results, slip value for two faces of a specimen were averaged.

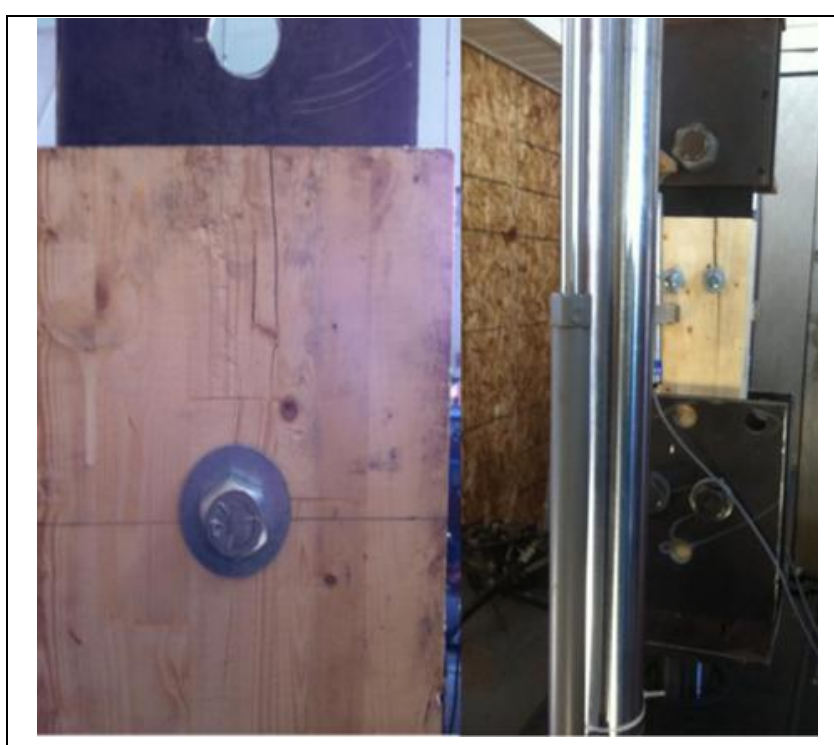

A

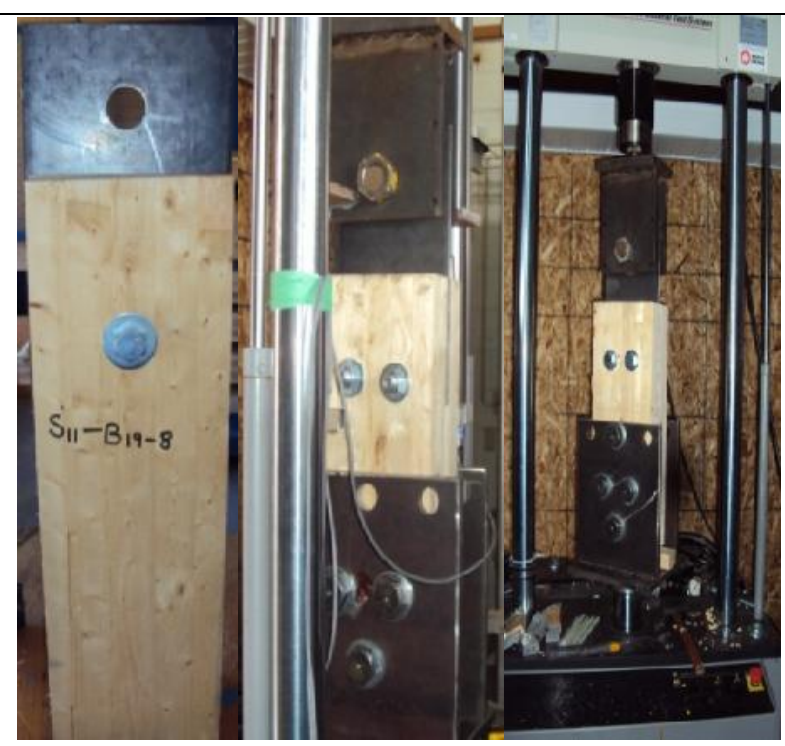

B

Figure 6: Tension test specimen and test configuration (1/2-inch bolts) (A) and Compression test specimen and test configuration (3/4-inch bolts) (B)

\section{RESULTS AND DISCUSSION}

All connections specimens failed due to exceeding the capacity of the glulam member, (Figures 7). As seen in the photographs, failure mechanisms transitioned from quite pseudo elasto-plastic responses to quite elasto-brittle responses depending on the combined effects of variations in bolt diameter, the thickness of the glulam member, the number of bolts, the moisture content of the glulam and whether the connection was loaded in tension or compression. Raw load-slip responses for specimens are shown in Figures 8 and 9. Immediately striking is that deformability and ductility was strongly affected by alteration of the glulam member moisture contents, irrespective of the bolt diameter and whether there were single or double bolts in connections. Dependence of maximum loads on the moisture contents of glulam members was generally less pronounced, with the exception of when members loaded by $1 / 2$ inch bolts were wetted to $17 \%$ moisture content. In the case of connections with $1 / 2$ inch bolts ultimate capacities were significantly reduced at the highest moisture content irrespective of whether there were single or double bolts. The difference between that sensitivity and absence of a similar sensitivity for connections with $3 / 4$ inch bolts is attributable to the former type being tested in tension and the latter type loaded in compression. Based simply on the load-slip responses a conclusion that can be drawn is that it is inappropriate to extrapolate sensitivities to alteration in $u$ from one case to another for the purpose of engineering design 
of connections. Table 2 summarises dependencies of controlling failure mechanisms on test variables. This table shows the ductility ratios for each combination of test variables, with ductility ratios being the ratio of slip at ultimate load to slip at the proportional limit load. In determination of those slip values the region of initial concavity in load-slip relationships was ignored, because that is associated with the take-up of slack in bolt holes and bedding of bolts when first loaded. It is clear from Table 2 that ductility ratio and failure mechanism are closely correlated, and that how the load is applied influences both of those characteristics.
Mechanical properties derived from connection test data are summarised in Table 3. In deriving elastic stiffness values and proportional limit loads any initial concavity in load-slip curves was ignored. In physical terms this amounts to ignoring initial non-linearity associated with take up of slack in bolt holes and bedding in of bolts after they had contacted surfaces of bolt holes. For consistence with analysis of embedment test data, the $5 \%$ of bolt diameter offset method was used to determine $P_{p l}$ values.

Table 2: Dependencies of ductility ratios and failure mechanism of test variables

\begin{tabular}{|c|c|c|c|c|c|c|c|c|c|}
\hline \multirow[t]{2}{*}{$d(\mathrm{~mm})$} & \multirow[t]{2}{*}{ \# bolt } & \multirow[t]{2}{*}{$t(\mathbf{m m})$} & \multirow[t]{2}{*}{$t / d$} & \multirow{2}{*}{$\begin{array}{c}u \\
(\%)\end{array}$} & \multirow{2}{*}{$\begin{array}{c}\text { Test } \\
\text { mode }\end{array}$} & \multirow[t]{2}{*}{$D^{*}$} & \multicolumn{3}{|c|}{ \# failing by mechanism } \\
\hline & & & & & & & Bear $^{* *}$ & Open ${ }^{* * *}$ & For $^{* * * * *}$ \\
\hline 12.7 & 1 & 90 & 7.1 & 8 & tens. & 1.28 & & $\checkmark$ & \\
\hline 12.7 & 1 & 90 & 7.1 & 12 & tens. & 3.50 & $\checkmark$ & & \\
\hline 12.7 & 1 & 90 & 7.1 & 17 & tens. & 3.17 & & & $\checkmark$ \\
\hline 19.1 & 1 & 130 & 6.8 & 8 & comp. & 2.58 & & $\checkmark$ & \\
\hline 19.1 & 1 & 130 & 6.8 & 12 & comp. & 3.75 & $\checkmark$ & & \\
\hline 19.1 & 1 & 130 & 6.8 & 17 & comp. & 3.54 & & & $\checkmark$ \\
\hline 12.7 & 2 & 90 & 7.1 & 8 & tens. & 2.02 & & $\checkmark$ & \\
\hline 12.7 & 2 & 90 & 7.1 & 12 & tens. & 2.29 & $\checkmark$ & & \\
\hline 12.7 & 2 & 90 & 7.1 & 17 & tens. & 2.30 & & & $\checkmark$ \\
\hline 19.1 & 2 & 130 & 6.8 & 8 & comp. & 1.92 & & $\checkmark$ & \\
\hline 19.1 & 2 & 130 & 6.8 & 12 & comp. & 1.93 & $\checkmark$ & & \\
\hline 19.1 & 2 & 130 & 6.8 & 17 & comp. & 2.09 & & & $\checkmark$ \\
\hline
\end{tabular}

Note: $D^{*}=$ ductility ratio, Bear ${ }^{* *}=$ bearing failure, Open ${ }^{* * *}=$ opening mode fracture and For $^{* * * *}=$ forward shearing mode fracture. 


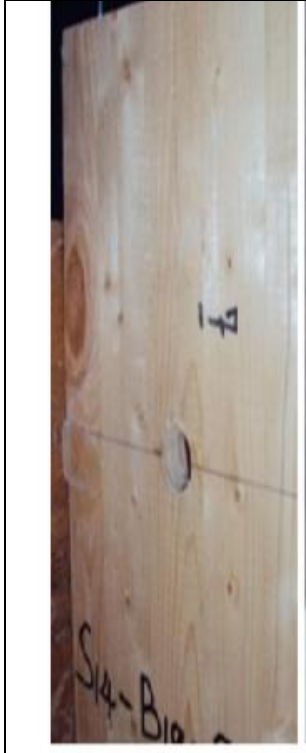

(a)

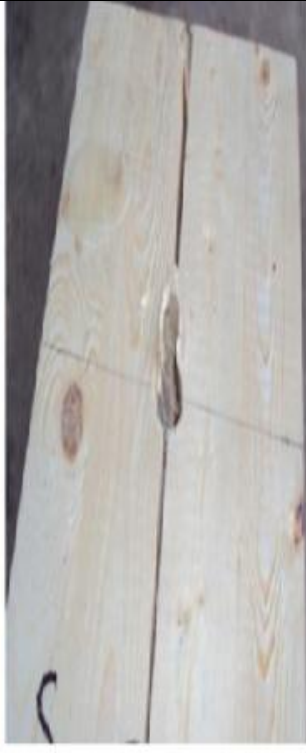

(b)

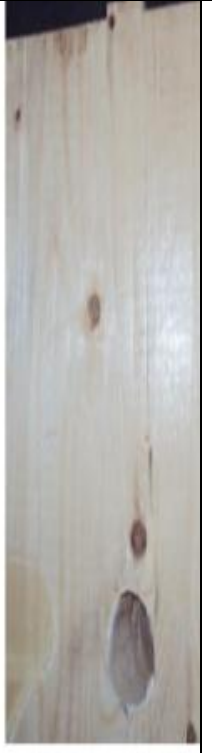

(c)

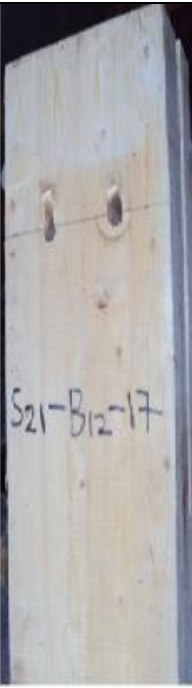

(a)

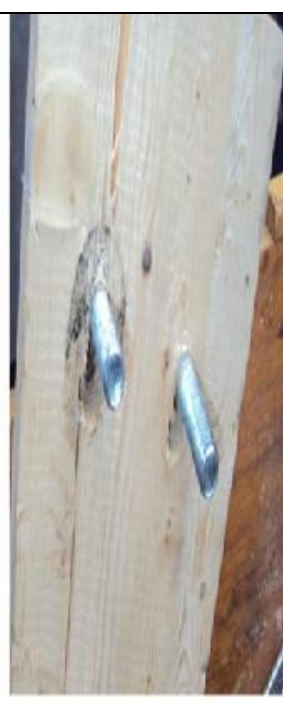

(b)

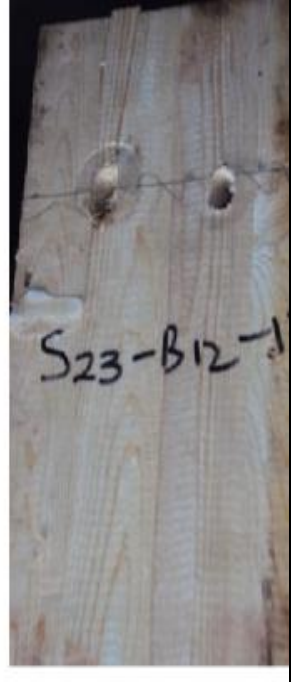

(c)

(a) Bearing failure (b) opening mode fracture (c) Forward fracture failure A

(a) Bearing failure (b) opening mode fracture (c) Forward fracture failure B

Figure 7: A typical failed glulam members loaded by a single bolt (A) and double bolts (B)

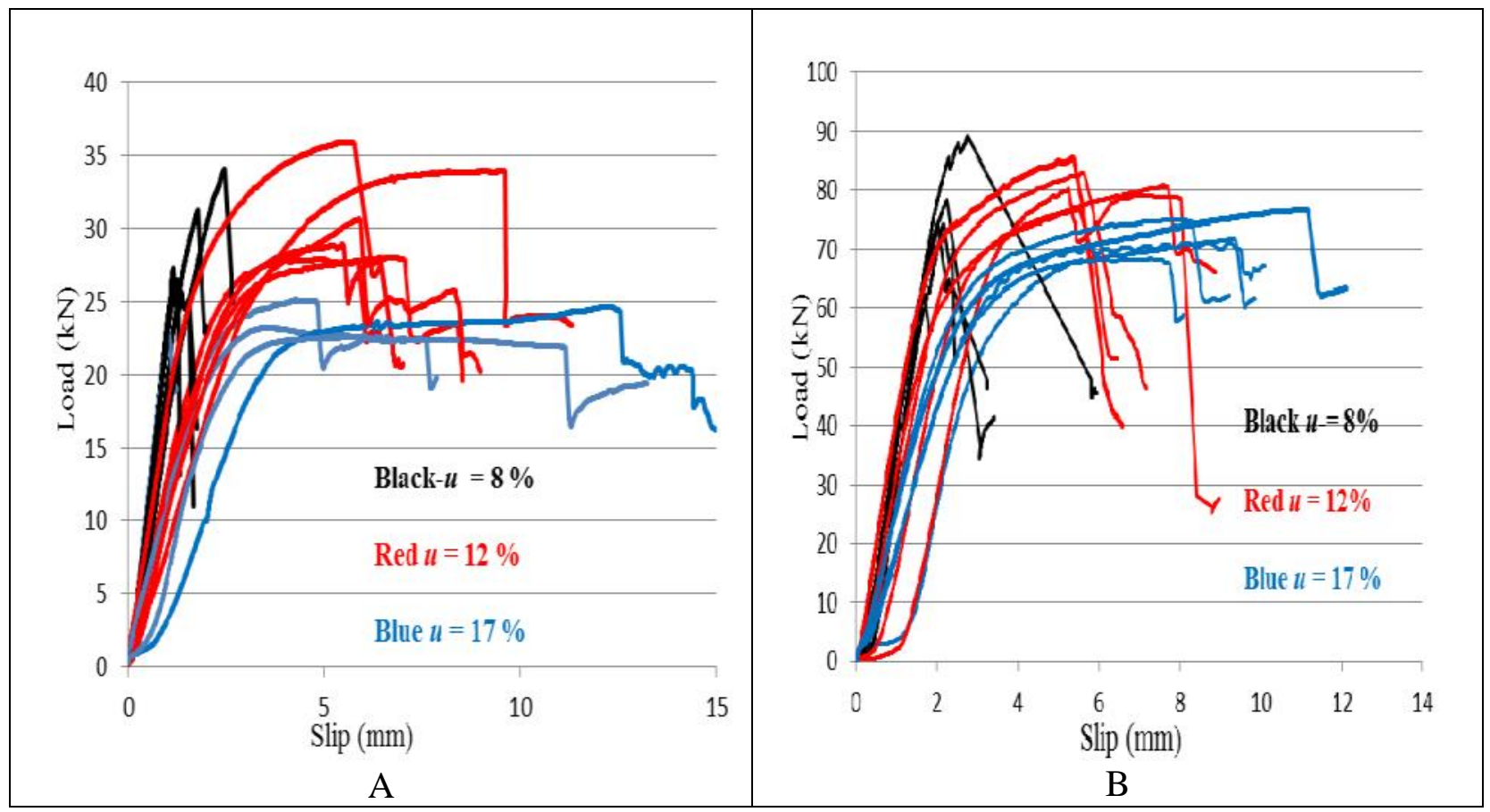

Figure 8: Load versus slip curves for connections with a single $1 / 2$ inch bolt (A) and with a single $3 / 4$ inch bolt $(B)$ 


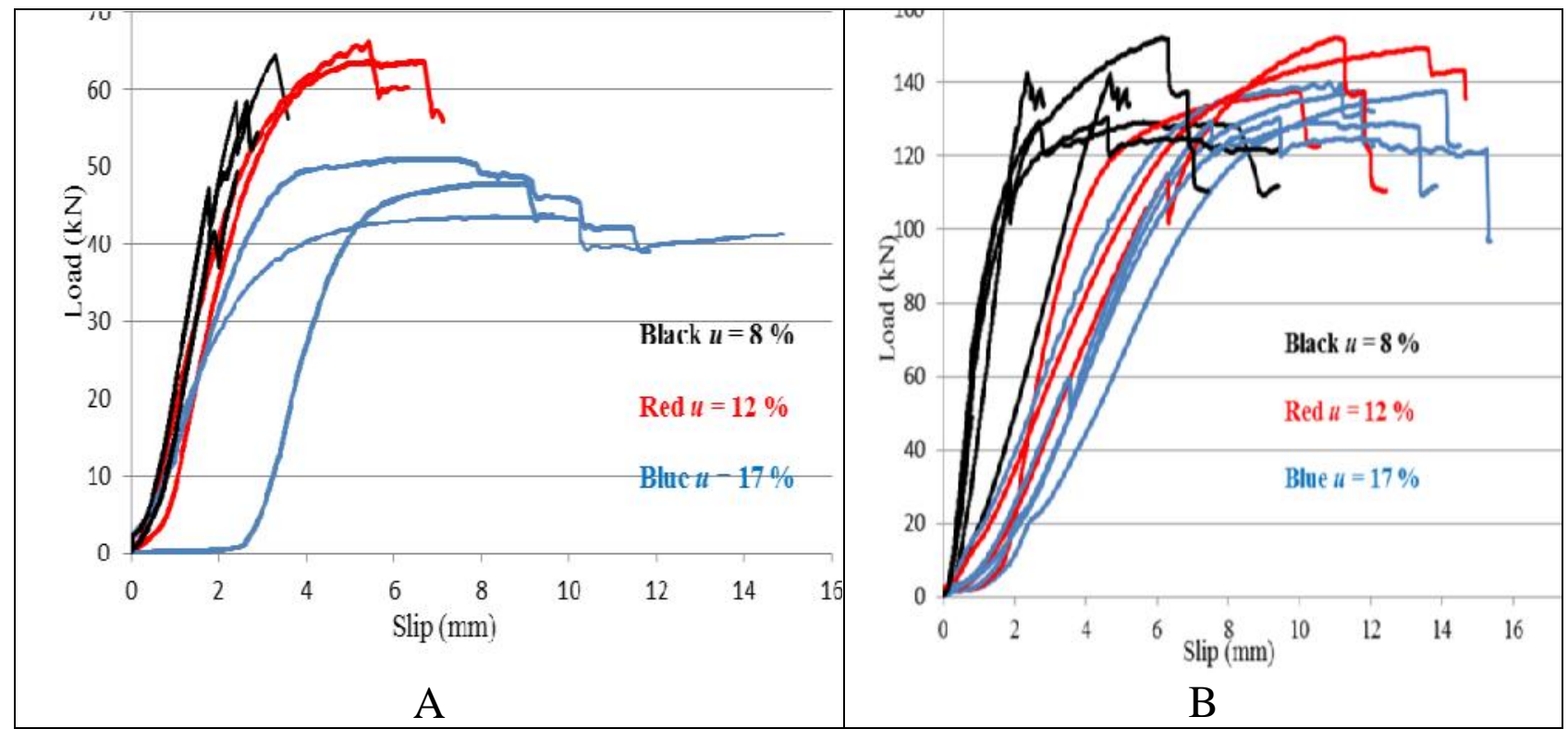

Figure 9: Load versus curves for connections with double $1 / 2$ inch bolts $(A)$ and with double $3 / 4$ inch bolts (B)

Table 3: Mechanical properties of bolted connections

\begin{tabular}{|c|c|c|c|c|c|c|c|}
\hline \multirow{2}{*}{$\begin{array}{l}\text { Specimen } \\
\text { type }\end{array}$} & \multicolumn{2}{|c|}{ Bolts } & \multicolumn{2}{|c|}{ Glulam } & \multirow{2}{*}{$\begin{array}{c}K \\
(\mathbf{k N} / \mathbf{m m})\end{array}$} & \multirow{2}{*}{$\begin{array}{c}\boldsymbol{P}_{\boldsymbol{p l}} \\
(\mathbf{k N})\end{array}$} & \multirow{2}{*}{$\begin{array}{l}P_{\max } \\
(\mathbf{k N})\end{array}$} \\
\hline & $d(\mathbf{m m})$ & $\#$ & $t(\mathrm{~mm})$ & $u(\%)$ & & & \\
\hline B12-S-8 & 12.7 & 1 & 90 & 8 & $64.26 *(8)$ & $26.9(10)^{*}$ & $29.2(9)^{*}$ \\
\hline B12-S-12 & 12.7 & 1 & 90 & 12 & $24.6(8)$ & $25.2(8)$ & $28.6(12)$ \\
\hline B12-S-17 & 12.7 & 1 & 90 & 17 & $18.7(14)$ & $21.9(8)$ & $24.5(11)$ \\
\hline B19-S-8 & 19.1 & 1 & 130 & 8 & $68.8(17)$ & $73.5(9)$ & 79.4(9) \\
\hline B19-S-12 & 19.1 & 1 & 130 & 12 & $24.64(6)$ & 69.8(5) & $75.5(11)$ \\
\hline B19-S-17 & 19.1 & 1 & 130 & 17 & $21.36(11)$ & $67.0(7)$ & $70.3(13)$ \\
\hline B12-D-8 & 12.7 & 2 & 90 & 8 & $25.2(9)$ & $68.1(7)$ & 78.7(9) \\
\hline B12-D-12 & 12.7 & 2 & 90 & 12 & $23.51(11)$ & $72.6(8)$ & $75.3(7)$ \\
\hline B12-D-17 & 12.7 & 2 & 90 & 17 & $10.35(8)$ & 66.7(11) & 73.4(10) \\
\hline B19-D-8 & 19.1 & 2 & 130 & 8 & $52.14(12)$ & $124.8(12)$ & $147.8(8)$ \\
\hline B19-D-12 & 19.1 & 2 & 130 & 12 & $48.12(7)$ & 121.1(9) & 142.9(9) \\
\hline B19-D-17 & 19.1 & 2 & 130 & 17 & 17.1(10) & $117.5(4)$ & $129.5(7)$ \\
\hline
\end{tabular}

*Average values, with Coefficient of Variance in $(\%)$ in parenthesis.

Table 4 shows average mechanical property values normalised relative to those of specimen type B12-S-12. This shows the proportional effects of variations in bolt diameter, the number of bolts in a connection, member thickness and moisture content of the glulam. Effects of test variables on initial stiffness of connections was very strong and only partially explainable by the well-known inverse relationship between wood stiffness properties and moisture content, $\mathrm{u}$ values below the fibre saturation point (FPL, 2010).
As can be seen, with the exception of the effect of alteration in the moisture content of the glulam, the ratios of strength properties $\left(P_{p l}\right.$ and $P_{\max }$ values) are not intuitively obvious, and effects of interactions of the test variables are highly complex and not easily explainable. Explanations for what was observed lie in how combinations of variables alter the deformation and failure mechanism. However, even without use of complex analytical tools of investigation it can be reliably stated that the observed 
influences of variable strongly reflected due to wetting or drying. distortions of glulam members that occurred

Table 4: Normalised average mechanical properties of bolted connections (relative to those for type B12-S-12)

\begin{tabular}{|c|c|c|c|c|c|c|c|}
\hline \multirow{2}{*}{$\begin{array}{l}\text { Specimen } \\
\text { type }\end{array}$} & \multicolumn{2}{|c|}{ Bolts } & \multicolumn{2}{|c|}{ Glulam } & \multirow[t]{2}{*}{$K$} & \multirow[t]{2}{*}{$P_{p l}$} & \multirow[t]{2}{*}{$P_{\max }$} \\
\hline & $d(\mathrm{~mm})$ & $\#$ & $t(\mathrm{~mm})$ & $u(\%)$ & & & \\
\hline B12-S-8 & 12.7 & 1 & 90 & 8 & 2.65 & 1.07 & 1.02 \\
\hline B12-S-12 & 12.7 & 1 & 90 & 12 & 1.00 & 1.00 & 1.00 \\
\hline B12-S-17 & 12.7 & 1 & 90 & 17 & 0.44 & 0.87 & 0.86 \\
\hline B19-S-8 & 19.1 & 1 & 130 & 8 & 6.93 & 2.92 & 2.78 \\
\hline B19-S-12 & 19.1 & 1 & 130 & 12 & 2.89 & 2.77 & 2.64 \\
\hline B19-S-17 & 19.1 & 1 & 130 & 17 & 1.51 & 2.64 & 2.46 \\
\hline B12-D-8 & 12.7 & 2 & 90 & 8 & 4.97 & 2.68 & 2.75 \\
\hline B12-D-12 & 12.7 & 2 & 90 & 12 & 2.34 & 2.86 & 2.63 \\
\hline B12-D-17 & 12.7 & 2 & 90 & 17 & 1.65 & 2.63 & 2.57 \\
\hline B19-D-8 & 19.1 & 2 & 130 & 8 & 6.55 & 4.91 & 5.17 \\
\hline B19-D-12 & 19.1 & 2 & 130 & 12 & 2.98 & 4.77 & 5.00 \\
\hline B19-D-17 & 19.1 & 2 & 130 & 17 & 1.89 & 4.63 & 4.53 \\
\hline
\end{tabular}

where symbol $\mathrm{K}=\mathrm{KN} / \mathrm{mm}, \mathrm{P}_{\mathrm{pl}}=$ load before failure and $\mathrm{P}_{\max }=$ Maximum load at failure

Firstly, alteration of glulam moisture content changed the sizes of holes in members which in all cases altered the way in which bolts contacted initially and as load was increased. Secondly, in the case of connections with two bolts either shrinking or swelling of the glulam member altered the relative positions bolt holes in glulam and steel plate members. Consequently, interference fit binding bolts increased due to post fabrication changes in glulam member moisture contents. Although to specifics of the consequences are complex, it appears that for connections that join together steel and glulam moisture content related adjustment factors should depend on how the fasteners are arranged and not simply on the moisture conditions of the glulam at the time of fabrication and during service.

\section{CONCLUSIONS}

The conclusion to be drawn from the results reported here is that accounting for effects of variables (like size and number of bolts, member thicknesses and moisture contents of wood members) during engineering design of connections does not lend itself to simple approaches. This underpins the need to as a minimum employ mechanics-based approaches which explicitly take account of all relevant deformation and failure mechanisms. Post-fabrication moisture content changes strongly influence the mechanical response characteristics of bolted connections wherein a steel plate member is joined to a glulam member by one or more laterally loaded bolts that load the glulam nominally parallel to the grain. The effects of either post-fabrication wetting or drying of the glulam member prior to loading are stronger than can be attributed simply to moisture change induced alteration of mechanical properties of that material. Physical changes like glulam expansion or shrinkage as moisture content changes and development of associated temporally varying moisture stress gradients are important and need to be accounted for to understand and predict how connections in timber structures behaves. Experimental on two-bolt connection tests in this study confirmed that connections with multiple dowel-type fasteners present challenges that lie beyond what was achievable through this 
study. In particular it was observed that brittle failure modes come into play with the natures of such failures depending on effects of both moisture and mechanical external loads.

\section{RECOMMENDATIONS}

The work presented in this paper has shown that humidity changes can have a negative effect on capacities of bolted connection in glulam structures. However, in the final analysis engineers need to know, or at least be told by design codes how to recognise and design against the possibilities and influences. The following recommendation can be taken into account for future studies.

- Determination of what types of connection details mitigate the possibility of unwanted phenomena like shrinkage cracks and brittle failure mechanisms.

- Development of numerical modelling methods that can predict, and can be used to avoid, unwanted phenomena like shrinkage cracks and brittle failure mechanisms in timber connections.

- The existing code of practice should incorporate the effect of moisture in the design of timber connection.

\section{REFERENCES}

Asiz A. and Smith I. (2009). Study on differential shrinkage in hybrid multi storey timber concrete building. In publication, University of New Brunswick, Fredericton NB, Canada.

Dinwoodie J.M. (2000). Timber: Its nature and behaviour. Second edition, E. \& F.N. Spoon, London.

Eriksson J. (2005). Moisture transport and moisture induced distortions in timber an experimental and numerical study. $\mathrm{PhD}$ Thesis, Chalmers University of Technology, Gothenburg, Sweden.

Forest Products Laboratory (2011). Wood as an engineering material. Handbook,
Washington, DC: US Department of Agriculture, 466p.

Canadian Standards association (CSA) (2009). Engineering design in wood, Standard 086-09, CSA, Toronto, ON.

Canadian Standards Association (1994).

Engineering design in wood. Standard 086-09, CSA, Toronto, Canada.

Johansen K.W. (1949). Theory of timber connections, Publications for International Association for Bridge and Structural Engineering, Zurich, Switzerland, 9: 249-262.

Jönsson J. (2004). Internal stresses in the cross-grain direction in glulam induced by climate variations. Holzforschung, 58: 154-159.

Kharouf N., McClure G. and Smith I. (2005). Postelastic behavior of singleand double-bolt timber connections. Journal of Structural Engineering, American Society of Civil Engineers, 131(1): 188-196.

Mirianon F., Fortino S., and Toratti T. (2008). A method to model wood by using ABAQUS finite element software: Part 1 - constitutive model and computational details. Publications 687, Technical Research Centre, Espoo, Finland.

Ormarsson S. (1999). Numerical analysis of moisture-related distortions in sawn timber. $\quad \mathrm{PhD}$ Thesis, Chalmers University of Technology, Gothenburg, Sweden.

Quenneville J.H.P. and Mohammed M. (2000). On the failure modes and strength of steel-wood-steel bolted timber connections loaded parallel-tograin. Canadian Journal of Civil Engineering, 27: 761-773.

Quenneville J.H.P. and Mohammed M. (2001). Design method for bolted connections loaded perpendicular-tograin. Canadian Journal of Civil Engineering, 28: 949-959.

Ranta-Maunus A. (2003). Effects of climate and climate variations on 
strength. In: Timber engineering. England, 153-167.

Rammer D.R. and Winistorfer S.G. (2001). Effect of moisture content on dowel-bearing strength. Wood and Fiber Science, 33(1): 136-139. Gothenburg, Sweden.

Smith I., Snow M., Asiz A. and Vasic S. (2006). Failure Mechanisms in Wood based materials: A review of discrete, continuum, and hybrid finite element representation. Selected article from 7 th WCCM, Los Angeles, USA, 61: 352359.
Smith I., Landis E. and Gong M. (2002). Fracture and fatigue in wood. John Wiley and Sons, Chichester, UK.

Sjodin J. (2007). Strength and moisture aspect of steel -timber dowel joint in glulam structures - An experimental and Numerical study. Doctoral Thesis, Växjö University, Sweden.

Whale L.R.J. (1988). Deformation characteristics of nailed or bolted joints subjected to irregular short- or mediumterm lateral loading. $\mathrm{PhD}$ Thesis, London South Bank University, London, UK. 